\title{
Future direction of surgical training and services in Sri Lanka
}

\author{
Third of a three part series envisioning the future of \\ training and services of the surgical specialties in \\ Sri Lanka
}

\section{Future directions of breast surgery in Sri Lanka}

Breast surgery has traditionally remained primarily within the scope of general surgeons and Oncological Surgeons in Sri Lanka. While this has ensured the availability of surgical treatment for diseases of the breast at all secondary and tertiary care hospitals, a relative lack of advancements and availability of newer techniques were observed in Sri Lanka, especially when compared with other branches of general surgery including gastrointestinal and hepatobiliary surgery. For instance, sentinel lymph node biopsy (SLNB) and wide local excision (WLE) for breast cancer are not offered on a regular basis in Sri Lanka at present [1], although SLNB and WLE have been the routine practice and included as the standard of care in most guidelines for over two decades [2, 3]. Many factors are known to have contributed to this situation including lack of training, heavy workload, lack of availability of mammography and other advanced imaging and lack of pathology services for intraoperative assessment of sentinel lymph nodes [4].

With the objective of improving the quality of surgery for breast disease, Sri Lanka Society for Breast Surgeons (SLSBS) was established in 2021. These objectives are highlighted in the vision of SLSBS which is to "Ensure the delivery of equitable high-quality breast surgical care throughout Sri Lanka". By providing a platform in sharing latest developments in breast disease and surgery, SLSBS hopes to provide its members with the opportunities to learn from experts in the field as well as sharing knowledge and learning from each other's experiences. Furthermore, SLSBS is expected to provide the platform for all surgical specialties working with diseases of the breast to obtain the necessary infrastructure and resources for provision of high-quality breast surgical care all throughout Sri Lanka.
SLSBS has identified several key areas as immediate priorities to improve the quality of treatment of breast disease in Sri Lanka.

1. Establishment of breast clinics at all teaching and district general hospitals

2. Ensure the availability of at least one functional mammo graphic machine to all districts in Sri Lanka

3.Providing access to all general surgeons to multidisciplinary meetings (MDMs) that include Oncologists, Radiologists, Pathologists and Surgeons with special interest in breast surgery.

These approaches are expected to increase the recognition of breast surgery as a defined specialty in Sri Lanka and would also ensure the provision of new knowledge and coordination of care which ultimately would benefit women with diseases of the breast in Sri Lanka.

Dr A De Silva (President), Prof. S Senevirathne (Editor), Sri Lanka Society of Breast Surgeons.

\section{References}

1. Balawardena J, Skandarajah T, Rathnayake W, Joseph N: Breast cancer survival in Sri Lanka. JCO global oncology 2020, 6:589599.

2. ASCO Guideline Recommendations for Sentinel Lymph Node Biopsy in Early-Stage Breast Cancer: Guideline Summary. Journal of oncology practice 2005, 1(4):134-136.

3. Scarth H, Cantin J, Levine M, Care SCoCPGft, Cancer ToB: Clinical practice guidelines for the care and treatment of breast cancer: mastectomy or lumpectomy? The choice of operation for clinical stages I and II breast cancer (summary of the 2002 update). CMAJ 2002, 167(2):154-155.

4. Gunasekera S, Seneviratne S, Wijeratne T, Booth CM: Delivery of Cancer Care in Sri Lanka. Journal of Cancer Policy 2018. 


\section{Future of Cardiothoracic and Thoracic Surgery in Sri Lanka}

Cardiothoracic Surgery in our Island nation has improved to great heights over the last two decades. However, there is still a lot more work to be done in order to provide a high-quality service to our patients, in keeping with world standards. There are mainly two arms to this future development. They are improving the accessibility to cardiothoracic surgical services and super-specialization of the specialty.

The current number of surgeries performed seem to be thoroughly inadequate to keep up with the ever-growing demand. This leads to long waiting lists resulting in increased mortality and morbidity among patients awaiting surgery. We hope to overcome this by setting up a couple of more centers, and increasing the capacity of the existing units. The aim would be to centralize services and have a few high-volume centers to cope with the ever-increasing demand for surgery. The National Heart Centre to be set up in Colombo will be the pinnacle of this effort.

Once the number of commonly performed cardiothoracic surgeries increase, then we will be able to concentrate on super-specialization in order to offer the full range of cardiothoracic surgical services currently practiced across the world, to our patients. These include Heart and Lung transplant, ECMO, minimally invasive cardiac surgeries and arrythmia surgery. The heart transplant programme although commenced, need a boost and revival while the ECMO programme which has been off ground for a while is increasingly being used to salvage the critically ill patients. Minimally invasive cardiac surgeries have also commenced in the form of MIDCAB. However, this needs to be extended to minimally invasive valve surgeries, etc.

Paediatric cardiothoracic surgical services have improved tremendously over the past 15 years after the commencement of a separate service which now caters to approximately half of the yearly need for newly diagnosed patients. However, the capacity needs to be significantly increased not only to manage the new patients each year but also to cater to patients deferred surgery each year and to patients needing repeated interventions. The worldwide goal in paediatric cardiothoracic surgery is to provide timely surgery for all the patients with congenital heart disease. To achieve this in Sri Lanka, trained surgeons in paediatric cardiac surgery are the prime necessity. Measures are underway to create the specialty of paediatric cardiothoracic surgery by year 2022 which will pave the way to increase the number of paediatric cardiothoracic surgeons to achieve the above goal and help establishment of new centers providing the service. This will help to expand the service to establish a Grown-Up Congenital Heart [GUCH] programme for the country, a paediatric Extra Corporeal Life Support [ECLS] service, paediatric heart transplantation and to offer complex biventricular repairs and surgery for hypoplastic left heart syndrome in the time to come.
Thoracic surgical service had been established at Chest Hospital, Welisara several decades ago. This has been later named as the National Hospital for Respiratory Diseases [NHRD]. The new era of dedicated Thoracic surgery with modern facilities such as VATS [Video Assisted Thoracic Surgery] began in 2007 and has evolved since then. Now there are four board certified Thoracic surgeons. Currently NHRD is the only tertiary referral center for the entire country. It provides surgical and bronchoscopic procedures for diagnosis and treatment of various chest related pathologies ranging from infections, malignant diseases to complicated chest trauma. With the qualifying of more surgeons and the improvement of infrastructure, the services could be expanded to the level of performing Lung transplantation and Robotic surgery. The establishment of new units will improve accessibility in the future.

Dr A. D. Kapuruge [President], Dr M De Soysa [Secretary], Dr K Singappuli, Dr S Handagala and Dr T Harishchandra [ Editor] of Association of Cardiothoracic Surgeons.

Progress and future of endocrine surgery in Sri Lanka Endocrine surgery is an emerging specialty world over [1]. The specialty of endocrine surgery in Sri Lanka had very humble beginnings and it has progressed rapidly as the Postgraduate institute in of Medicine [PGIM] gave due recognition by making general surgery with special interest in endocrine surgery one of the specialties recognized by the PGIM for board certification and 3 surgeons have chosen this specialty so far. It is evident that endocrine surgery as a standalone specialty will develop in Sri Lanka with the passage of time. Those undertaking treatment of endocrine disorders must encourage more people to take up the specialty and fine tune the training process in order to deliver the best in endocrine surgery to the patients [1,2\&3].

In terms of the service commitment in endocrine surgery most general surgeons and surgeons of other disciplines undertake thyroidectomy and there is a need to standardize management of surgical endocrinology with development of guidelines. While some guidelines are available for thyroid diseases, much more needs to be done to optimize management. Majority of the endocrine surgical work will be dealt with by general and other surgeons in the foreseeable future. There is a need to develop at least 3 or 4 centres of excellence to deal with difficult, complex, and recurrent surgical endocrine problems to offer the best care to patients.

The role of technology in endocrine surgery is an issue that needs careful consideration especially in the future. Advances in technology have undoubtedly helped the standard of care but the access to investigations and treatment is not equitable. It would be desirable to have well equipped laboratories and radiology departments which will provide access to investigations of the four main endocrine organs namely the thyroid, parathyroid, adrenal, and endocrine pancreas, to all patients, at least in teaching hospitals. 
In terms of surgery and management, the role of the endoscope, the robot and other newer devices in endocrine surgery need to be clearly defined for Sri Lanka. The main issues that need to be resolved are availability, sustainability, safety, and the cost effectiveness of these techniques. The mere possibility is not a criterion to recommend a procedure for standard practice, the relevant factors and circumstances must be analyzed before a decision is made $[4,5]$. While there is no doubt that technological advances will need to be incorporated into the practice of endocrine surgery in Sri Lanka, a careful deliberation and prudent decision making is the need of the hour.

There is a lamentable lack of robust evidence in the practice of endocrine surgery world over. In Sri Lanka there is hardly any reliable evidence emanating from the main centres. The need to collect our own data and make the practice of endocrine surgery evidence guided cannot be overemphasized [3].

There is much work to be done in terms of policy making, training, service provision and research in endocrine surgery in Sri Lanka. The process has been started and the need is to sustain the effort and move the specialty forward so that endocrine surgery in Sri Lanka will be able to match the best practices in the region, if not the world over.

\section{ProfR Fernando ${ }^{1}$, Dr A Banagala ${ }^{2}$ and Dr S Seneviratne ${ }^{1}$ North Colombo Teaching Hospital \\ ${ }^{2}$ National Hospital of Sri Lanka}

\section{References}

1. Leigh Delbridge Endocrine surgery - a 23-hour specialty? Journal compilation (C) 2009 Royal Australasian College of Surgeons doi: 10.1111/j.1445-2197.2009.04460.x

2. J. J. Earnshaw and D. Alderson. Sustainable global surgery BJS 2014; 101:1-2

3. Ranil Fernando Global trends and equitable care in endocrine surgery. The Sri Lanka Journal of Surgery 2017;35[4]: 1-2

4. Cabot JC, Lee CR, Brunaud L, Kleiman DA, Chung WY, Fahey TJ III, Zarnegar R. Robotic and endoscopic transaxillary, thyroidectomies may be cost prohibitive when compared to standard cervical thyroidectomy. Surgery 2012; 152:101624.https://doi.org/10.1016/j.surg.2012.08.029

5. Nicole R. Jackson ,Lu Yao, Ralph P. Tufano, Emad H. Kandil Safety of robotic thyroidectomy approaches: Meta-analysis and systematic review Head \& Neck Volume 36, Issue 1: 137-143,January 2014

\section{Future direction of general surgery}

At the onset, surgeons used to perform surgeries on the whole body. However, with the advent of precise knowledge and high precision skills lead to ramification of surgery into speciality surgery and general surgery [1].

Still, the general surgeons carried out most common surgical procedures and bore the brunt of the surgical emergencies including trauma. At this stage, who would care for trauma [non-orthopaedic] and other emergencies, where and how the surgical training would be given, and how to keep up with the increasing knowledge and growing complexity of the surgical procedures were the main challenges surgeons of this country faced.

\section{Special Interest training}

To face these challenges, the Association of General Surgeons of Sri Lanka [AGSSL] and the Speciality Board of General Surgery of the Post Graduate Institute of Medicine [PGIM] of Sri Lanka introduced a significant change to their training schedule by introducing a special interest to their doctorate, the MD surgery degree. There are seven such domains of special interests [2].

With this change, we expect to have surgeons with exceptional skills in a particular domain and supervise and manage more general surgical problems and emergencies.

\section{Special interest associations and professional bodies}

Already few special interest associations have been formed under the AGSSL and collaborations established with several others. Main objective of this move is to engage with relevant surgical and non- surgical colleagues. In future, these associations will be further strengthened to nuture the special interests of general surgery.

\section{Cluster system}

The need to have a good inter-hospital and inter-unit referral system cannot be overemphasized. For example, one general surgeon could refer a patient to his colleague trained in a particular special interest.

The general surgeons will be proposing and supporting a cluster hospital system to promote sharing hospital resourcesboth human and infrastructure. The cluster would consist of a few close-by hospitals functioning as one trust. This will allow general surgeons to improve their interest while attending to day to day work. All necessary infrastructure will be provided to the particular hospital while the post should be advertised with the relevant interest.

Above is a challenging but worthwhile task that would need the support of the AGSSL, the College of Surgeons of Sri Lanka [CSSL], the Health Ministry, and many other stakeholders. We have already initiated a dialogue with the Ministry of Health in this regard, who have accepted the proposal on principle.

\section{Continuous Professional Development, Audit and Research}

The other areas that need improvement include maintenance of registries and records, research, and audit. Finally, multidisciplinary management teams would be the base for a protocol-driven system, which is essential for the equitable delivery of modern healthcare. High volume patient turnover and continuous professional development would also 
facilitate collaboration with the international surgical fraternity.

Surgery is an evolving field, and the general surgeons of Sri Lanka are very much keeping abreast of these developments to serve the nation in the years to come.

\section{Dr H.L.D.S Ariyaratne [President] and Dr U Samarajeewa} [Secretary], Association of General Surgeons of Sri Lanka.

\section{References}

1. Sabiston Textbook of Surgery, Chapter 1,2-19. page 15

2. https://pgim.cmb.ac.lk/index.php/surgery/\#1477543420515f32d1421-dfdb

3. Analysing public sector institutional capacity for health work force governance in the South-East Asia region of WHO

G Cometto, E Nartey, T Zapata, M Kanda, Y Md... - Human resources for health, 2019

4. https://scholar.google.com/scholar?oi=bibs\&cluster=12213511 $413639570444 \&$ btnI $=1 \&$ hl $=$ en

Hepato-pancreatico-biliary [HPB] surgery in Sri Lanka Historically, HPB surgery was performed in relatively small numbers by the general surgical fraternity. Noteworthy amongst them were Dr K Yoheswaran at the Sri Jayawardenapura General Hospital, renowned for his prowess in pancreatic surgery and Professor Mohan De Silva who pioneered pancreatic surgery, at the Colombo South Teaching Hospital. Professor A H Sheriffdeen performed major liver resections with limited resources during his time at the University Surgical Unit of the NHSL.

The cornerstone for the progress of HPB surgery in Sri Lanka has been subspeciality training. Over the past two decades, Sri Lankan surgical trainees have trained in high volume, tertiary HPB surgery units in the UK, Australia and Hong Kong and obtained board certification in Gastrointestinal or General Surgery with a special interest in HPB surgery. This has led to an expansion in the spectrum of HPB surgery performed with vastly improved outcomes. Several units in teaching hospitals now have dedicated HPB surgery divisions, that serve as referral centres and perform complex HPB surgery including liver transplantation with outcomes comparable to international centres of excellence.

The Professorial Surgical Units at Colombo South Teaching Hospital [CSTH], Kalubowila, under Professor Aloka Pathirana, North Colombo Teaching Hospital [NCTH], Ragama under Professor Rohan Siriwardena, National Hospital of Sri Lanka [NHSL], Colombo under Professor S Sivaganesh and Teaching Hospital, Peradeniya [THP] under Professor Arinda Dharmapala perform the bulk of advanced HPB surgery in the country. The work in these units is augmented by advanced ERCP and endosonographic facilities and diagnostic and interventional radiological services at these centres.
In addition to the establishment of tertiary HPB surgical units, the concurrent development of specialist services in diagnostic imaging, interventional radiology, advanced ERCP and endosonography, critical care, oncology, and the multidisciplinary approach to complex pancreatic pathologies have had a major impact in improved care and outcomes in these patients. A new group of well-trained HPB surgeons taking up appointments at these established centres including Dr Suchintha Tillakaratne [NCTH], Dr Buddhika Dassanayake [THP], Dr Duminda Subasinghe [NHSL], Dr Malith Nandasena [CSTH], Dr Prabath Kumarasinghe and Dr Sandun Bulathsinhala are guaranteed to expand Sri Lankan HPB surgery to new horizons in the years to come.

The Sri Lanka Hepato-Pancreato-Biliary Association [SLHPBA] an affiliate of the International Hepato-PancreatoBiliary Association [IHPBA] has served to foster links with regional and international experts in HPB surgery and enhance training opportunities. Over the coming years the SLHPBA has an ambitious agenda towards developing HPB surgery in the country. This includes enhanced educational activities in the form of biannual HPB master classes, the development of interactive online training modules for postgraduate trainees, establishing a national HPB surgery registry and formulation of national care pathways and guidelines for common conditions.

The establishment of care pathways leading to tertiary HPB surgical and liver transplantation units will go a long way to deliver state of the art care and improved outcomes. Clustering HPB surgeons, allied specialities and infrastructure in these tertiary units also facilitates efficient use of manpower and equipment in the years to come.

\section{Prof S Sivaganesh [President], Sri Lanka Hepato-Pancreato- Biliary Association [SLHPBA]}

Progress and future of colorectal surgery in Sri Lanka World's first hospital dedicated to diseases of a single organ was started by Frederick Salmon in 1835 in City of London, United Kingdom and still lead the way in colorectal surgery as St Mark's hospital [1]. Worldwide, colorectal surgery has become a rapidly evolving specialty over recent years. Newer technologies and techniques are increasingly being used and have become part of surgical armamentarium [2]. Colorectal surgery gained it's recognition with introduction of 'colorectal interest in general surgery' and has become one of the most sort after training opportunities as part of the residency training by Postgraduate Institute of Medicine [PGIM] in Sri Lanka.

Existing researches indicated patients undergoing colorectal surgery may require a second operation 2 to $5.8 \%$ of the time [3]. Recognition of colorectal cancer as one of the successfully screened, prevented and treated conditions with emerged evidence on better outcome of colorectal interventions [4] carried out by 'colorectal surgeons' 
highlighted the need to fine tune the skills of surgical trainees by a dedicated training process to deliver improved patient outcome.

At present there is no consensus and agreement in terms of managing various colorectal conditions in Sri Lanka thus stressing the need to implement guidelines, registries on diseases, regular national audits, and research. The lack of reliable data platforms on surgeries conducted within the country highlights the need for a registered database. Formulation of national guidelines, implementation of national registries on colorectal cancer, familial colorectal conditions, inflammatory bowel disease has started since the inception of Sri Lankan Association of Colorectal Surgeons[SLACS] in July 2021.

Minimal invasive surgery including laparoscopy and robotic surgery has been a major revolution in surgery and clearly has become a core technique in colorectal surgery [5]. Sri Lankan colorectal surgeons are acquiring mastery of the applications of laparoscopy but denied of opportunity to exposure in robotic surgery in evolution [6]. A number of new approaches have already evolved, some even aggressively marketed, even though they have not yet been sufficiently established or their impact adequately studied. It should be in the interest of colorectal surgical specialty to develop objective guidance to such efforts and determine the goals and possible benefit/risk analysis. They are yet to apply advancements in managing patients while critically assessing the role of some minimally invasive approaches, application of artificial intelligence, preoperative patient optimization, or comparing the outcomes of different innovative approaches to colorectal diseases.

Even though bulk of colorectal work is being carried out by various specialists in surgery, gastroenterology, oncology, pathology, and radiology; Sri Lanka as a country has an unmet need of at least one or two centers of excellence where advanced and complex colorectal and abdominal surgical care can be delivered in relevant specialties. It would provide a common platform to train and guide future colorectal surgeons in taking Sri Lankan surgical skills to world arena.

Dr W Wijenayake [President], Sri Lankan Association of Colorectal Surgeons [SLACS]

\section{References}

1. About Us - St Mark's Hospital [Internet]. [cited 2021 Nov 14]. Available from: https://www.stmarkshospital.nhs.uk/about/

2. Pandey D, Yen CF, Lee CL, Wu MP. Electrosurgical technology: Quintessence of the laparoscopic armamentarium. Gynecology and Minimally Invasive Therapy. 2014 Aug 1;3[3]:63-6.

3. Tevis SE, Kennedy GD. Hot Topics in Colorectal Surgery: Postoperative Complications: Looking Forward to a Safer Future. Clinics in Colon and Rectal Surgery [Internet]. 2016 Sep 1 [cited 2021 Nov 13];29[3]:246.

Available from:/pmc/articles/PMC4991963/
4. Pak H, Maghsoudi LH, Soltanian A, Gholami F. Surgical complications in colorectal cancer patients. Annals of Medicine and Surgery. 2020 Jul 1;55:13-8.

5. Trinh BB, Jackson NR, Hauch AT, Hu T, Kandil E. Robotic Versus Laparoscopic Colorectal Surgery. JSLS : Journal of the Society of Laparoendoscopic Surgeons [Internet]. 2014 [cited 2021 Nov 14];18[4]. Available from:/pmc/articles/PMC4254480/

6. Priyantha T G A. Surgery for Colorectal Cancer in Sri Lanka: Open to Laparoscopy. Sri Lanka Journal of Surgery. 2018 Apr $30 ; 36[1]: 10$.

Future Directions of Services and Training in Neurosurgery It is just more than a half century since establishment of Neurosurgery unit in Sri Lanka in 1956 under Dr Shelton Cabral [1]. Since then neurosurgery has progressed to a level where today is comparable to the international standard.

Dr Colvin Samarasingha well known neurosurgeon initiate and got down the first MRI machine into the country and installed at the NHSL. Introduction of microscopic neurosurgery was pioneered by Dr Lal Gunasekara the farther of modern neurosurgery. Novel chapter of neurosurgery began in 2010 when the state of art Neuro Trauma Centre was opened as a result of hard work done by Dr Sunil Perea [1], who revolutionized modern neurosurgery in Sri Lanka. Each and every neurosurgeon in the country has dedicated and contributed to the development of neurosurgery.

One of the major mile stone of neurosurgery in Sri Lanka was establishment of Neurosurgeons Association of Sri Lanka in 2006 under the leadership of Dr Jaliya Lokuketagoda to bring all neurosurgeons in the country together [1].

Initially there were only two neurosurgeon in the country for 22 million of population, but now the number has risen to 24 Neurosurgeons serving in all nine provinces, including private sector.

According to WHO criteria there should be 0.5 to 1 neurosurgeons per 100, 000 population, hence Sri Lanka need at least 110 neurosurgeons [7]. Major obstacle for not having adequate number of neurosurgeons in the country has been identified as the lack of a structured neurosurgery training program.

Our main objective for next five years is to establish Neurosurgery MD program there by attracting more trainees in to the system to full fill the minimum number of neurosurgeon requirement within next 25 years $[3,4]$.

As the number of neurosurgeons increase we are hoping to establish more fine subspecialties among neurosurgery improving the quality of neurosurgical care. The recent establishment of Paediatric neurosurgery unit at Lady Ridgway Hospital and Epilepsy Neurosurgery Unit at the NHSL provide a highly specialized service $[2,3,4]$. 
Despite most proportion of spinal trauma, degenerative spinal disease and almost all the spinal tumours being managed by the neurosurgeons, sometimes care given was not satisfactory due the time constraints. However our future plan of specialized spine centers intended to be establish in Ragama, Digana and Anuradhapura will cater for the whole nation [2]. Further expansion of neuro trauma care is another objective for the near future.

We as the association of Neurosurgeons of Sri Lanka are happy to declare that we are achieving our goals of development of neurosurgery in a timely fashion for the benefit of the public of Sri Lanka.

Dr Nirukshan Jayaweera [Consultant Neurosurgeon, Lady Ridgeway Hospital for Children], Neurosurgeons Association of Sri Lanka

\section{References}

1. Lokuketagoda JR, Gunasekara LW. Evolution of Neurosurgery in Sri Lanka. World Science 2011. http://www.worldsci.com/read.aspx?id $=80$

2. Health strategic master plan 2016 - 2025 ; curative services , Colombo Policy Analysis and Development Unit . Ministry of Health, 2016.

http://www.health.gov.lk/moh_final/english/public/elfinder/files /publications/HMP2016-2025/Curative\%20\%20Services $\% 20 \% 20$-.pdf

3. Health Master Plan 2017 and beyond, Recommendations for Neurosurgery, Neurosurgeons Association of Sri Lanka. [Proposal by NSASL] 15th September 2015.

4. Neurosurgery Carder Projection for 2020 and beyond. Neurosurgeons Association of Sri Lanka. [Proposal by NSASL] March 2015.

5. Neurosurgery Work Force in Australia Supply and Requiremnt, 1999-2010, Australian Medical work force Advisary Comittiee. 2000. http://amwac.health.nsw.gov.au

6. British Neurosurgical Work force plan 2000-2015, M J Neloson, April 2000.

7. The global neurosurgical workforce: a mixed-methods assessment of density and growth.

https://thejns.org/view/journals/j-neurosurg/130/4/articlep1142.xml.

\section{Future direction of Oncological surgery in Sri Lanka}

Oncological surgery in Sri Lanka cannot be separated from the history of the of Cancer Institute at Maharagama, which was built in 1961. Initially general surgeons with a special interest in head and neck surgery, oesophageal and other intra abdominal surgery, breast surgery as well as sarcoma surgeries were stationed at this hospital and performed complex cancer surgery resections and reconstructions. Over a period of time this hospital acquired a complete oncological infrastructure with facilities such as surgery, chemotherapy, target therapy, radiotherapy with latest therapy planning systems, bone marrow transplantation, immunohistochem-istry, PETCT etc. which paved way for a comprehensive multidisciplinary management of cancer patients under a single roof.

In this backdrop, Post graduate Institute of Medicine initially incorporated cancer surgery to the MD surgery registrar training programme. Surgical Oncology was later recognized as a as a separate training programme for senior registrar training consisting of 2 years of local post MD training followed by 1 or 2 years of overseas training. At present the recognized cancer surgery training units are located at Maharagama, Kandy, Galle and Kurunagala. There is also a separate speciality board for Oncological surgery to oversee the training programme. The Speciality board has laid down a prospectus for Oncological surgical training and this format has to be full filled by any current or future trainee to be eligible for accreditation in Oncological surgery.

The National Cancer Control Programme along with the ministry of health has putout a National Strategic Plan for future direction of Oncological facilities in Sri Lanka. As a part of this programme 9 regional cancer centers were developed to cover 9 provinces of the country and at present there 22 oncosurgeons in government service. The future projection is to further expand these units by upgrading existing facilities and the specialised cadre. In addition some oncosurgeons are attached to universities and some are permanently working in the private sector. So there is much potential to absorb many enthusiastic trainees to the exiting field of cancer surgery training of which has the hallmark of exposure to complex surgeries in high volume centers in a multidisciplinary setup .

Oncosurgical units currently provide complex Oncological resections, plastic surgical reconstructions, laparoscopic surgery, diagnostic and therapeutic endoscopy including stenting, chemotherapy port insertion, HIPEC and any other surgical support required by the cancer patients. All these OncoSurgery units work in close collaboration with the clinical oncology units in the same hospital. Regular multidisciplinary meeting with the Oncologist, Oncological surgeons, Pathologists and Radiologists are held to discuss complex and interesting cases thus providing best possible care to the patient. Addition of new facilities such as Robotic surgery and intra operative radiotherapy therapy are some areas we are lacking at present and should be thought as projects for future. We have developed strong collaborations with many high end centers such as Royal Marsden hospital UK, Christie Cancer hospital in Manchester and number of other hospitals in the UK and Australia who regularly request for our trainees. Sri Lanka association of Surgical Oncologist was also established to look into different aspects of oncological surgery.

In future we plan to specialize in different areas of Oncological surgery such as breast, endocrine, head and neck ,sarcoma etc. to give an overall better care to the patient. For 
these sub specialized surgeons to have adequate work in their chosen fields, we are currently looking at ways of improving infrastructure facilities and referral pathways .

\section{Dr K De Silva [President], Sri Lanka Association of Surgical Oncologists}

\section{The future direction of orthopaedic surgery}

Orthopaedic surgery is a rapidly advancing field where novel engineering technology is leveraged to improve patient care. The most recent advances in orthopaedic surgery are in the fields of diagnostics, reconstruction techniques for joint instabilities, and arthroplasty.

Better diagnostic techniques make our jobs easier and improve overall patient outcomes. Since Roentgen invented $\mathrm{X}$ rays in 1895, medical imaging has improved to a great extent. Currently, we rely on MRI scans for soft tissue pathologies, which has now evolved to 7 Tesla resolution and dynamic scans. CT scans have enabled better visualisation of bone; recent advances in 4D CT scans help us better understand joint instabilities and impingement.

Moving from low radiation options to no radiation options, biplanar videography has been validated to study small joint kinematics.

A low radiation option for fluoroscopy is available in the theatre, enabling the 'mini fluro scanner' for small joints safer for patients and surgeons. 'O-arm' imaging devices provide 3$\mathrm{D}$ visualisation and multiplanar image visualisation at the same time for complex spine and shoulder surgeries.

Arthroscopy is possible for every joint, enabling minimal access surgery. The chip-on-tip Nano Scope combines $1 \mathrm{~mm}$ imaging sensors, LED lighting, image management, and tablet controlling device. Nano Scope combined with WideAwake Local Anaesthesia No Tourniquet surgery [WALNT] helps perform diagnostic procedures at the bedside. This can massively reduce costs for operating theatres and facilitates patients' return to everyday life early.

Computer-assisted surgery [CAS] and robotic-assisted surgery [RAS] improve the positioning of implants during joint arthroplasties and spinal surgeries. Most studies have reported that computer-assisted navigation reduces the chances of implant malpositioning, improving the consistency of positioning and alignment.

3D printed models are used for complex fractures and osteotomies. In contrast to conventional templating, the current fracture templating is done on 3D models and 3D printed models. This gives the surgeon a better understanding of the reduction and fixation of a difficult fracture.

Moving forward with this technology, many developed countries use custom-made implants for challenging arthroplasty cases such as revisions and tumour reconstructions. The fractures are also given similar importance with custom made fixation devices and custom printed instruments/ cutting jigs.

Educating future Orthopaedic surgeons has reached new heights with 3D printed soft tissue models. Currently, there are $3 \mathrm{D}$ printed soft tissue models which almost simulate a real joint with ligaments. These are used for surgical training instead of cadavers, overcoming the costs for maintaining cadaver labs and avoiding ethical issues related to human cadaver use.

These advancements in every imaginable facet of Orthopaedics will transform how we treat patients and push the boundaries of what's possible. Ultimately, what matters are the patient outcomes and quality of life. My hope is that the future orthopaedic surgeon will have better tools and techniques to improve the lives of patients and achieve feats that we can only dream of.

\section{Dr Rukshan Sooriyarachchi [President], Sri Lanka Orthopaedic Association}

\section{Future of Paediatric Surgery in Sri Lanka}

The specialty of paediatric surgery in Sri Lanka, has grown progressively over the last 30 years. Even though specialised paediatric surgical services was offered in the country since 1960's, the appointment of the first board certified consultant paediatric surgeon took place in the early 1990's. Since then, about 25 paediatric surgeons have obtained board certification with the Post Graduate Institute of Medicine [PGIM] . Over the last few years, many trainees have also taken up the specialty of paediatric surgery, adding to the existing pool of qualified specialists in the near future.

Until a few years ago, Lady Ridgeway Hospital for Children [LRH] was the only training centre for paediatric surgical subspecialty training. Later on, teaching hospital - Kandy was recognised as a training centre a few years ago. Relevant measures are being undertaken for the accreditation of teaching hospitals Galle and Sirimavo Bandaranayake hospital - Peradeniya [SBH] as additional training centres in the near future and this will increase the capacity for training of future specialists in paediatric surgery, both local as well as international.

For a considerable period of time, specialised paediatric surgical services were available only in Colombo, Kandy, and Galle districts. Currently, the services have been expanded to cover most of the areas of the country and plans are underway to establish paediatric surgical units at each provincial general hospital level.

In the developed world, certain paediatric surgical services are being centralised resulting in the development of centres of excellence for provision of specialised services such as 
organ transplantation and management of rare, complex congenital anomalies such as bladder exstrophy [1]. In future, with the establishment of adequate paediatric surgical services across the country, centralisation of services could be achieved utilising main children's hospitals such as LRH \& $\mathrm{SBH}$.

Minimally invasive surgery is performed in most paediatric surgical centres in Sri Lanka, at present. In future, it will be expanded to include most common paediatric surgical conditions including neonatal conditions such as congenital diaphragmatic hernia, oesophageal atresia, duodenal atresia etc.

Paediatric urology forms a significant proportion of a paediatric surgeon's workload. In most parts of the world, it has emerged as a distinct subspecialty [2]. Plans are being developed to start a separate training program in paediatric urology and in the future, board certified paediatric urologists will be appointed to centres such as LRH and SBH.

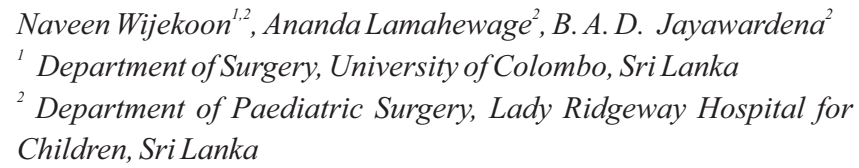

\section{References}

1. Durkin N, Davenport M. Centralization of Pediatric surgical procedures in the United Kingdom. Eur J Pediatr Surg. 2017 Oct;27[5]:416-421.

2. Gangopadhyay AN. Pediatric Surgery in rural India: Past, Present and Future. J Indian Assoc Pediatr Surg. 2020 JulAug;25[4]:193-194.

\section{Reinforcing national trauma system development in Sri Lanka}

\section{Perspective of a trauma burden in Sri Lanka}

Trauma accounts for $11 \%$ of the total global burden of disease. Approximately $90 \%$ of permanent and temporary disability due to injury occurs in low and middle-income countries [1-3]. Trauma has been the leading cause of hospitalization in Sri Lanka over the last two decades. In 2019 , approximately $1,136,000$ trauma patients were admitted to government hospitals. It is the 10th cause of hospital deaths in 2019 with reported 2000 cases [2]. High road crash fatality and injury rates on Sri Lanka's roads are undermining the economic growth and progress made over the past decade in reducing poverty and boosting prosperity. Estimated annual road traffic deaths per capita are twice the average rate in high-income countries and five times that of the best performing countries in the world. Available data indicate an average of 38,000 crashes annually which result in approximately 3,000 fatalities and 8,000 serious injuries. [5].

\section{Gaps in existing trauma care}

With World Health Organization [WHO] guidance, the
Ministry of Health, and Indigenous Medical Services [MoH] embarked on several major trauma system improvement projects. These measures include, accident and emergency policy [March, 2015], identifying emergency medicine as a post graduate specialist program [2012], establishing 1990 Suwasariya as field Emergency Medical System [2016], establishing disaster management center under disaster management council [2005] and implementation of national injury surveillance system [2017] [6-10]. The College of surgeons of Sri Lanka [CSSL] has been the main provider of trauma training in Sri Lanka with established courses including Primary Trauma Care [PTC], National Trauma Management Course [NTMC], Advanced Trauma Life Support [ATLS][11]. Aforementioned policy and governance structure has guided the existing comprehensive hospital network, with highly qualified health care staff towards reasonably sound trauma service in Sri Lanka. At the same time there is a recently established emergency ambulance service [Suwaseriya] providing prehospital care. The disaster management center coordinated by the National Council for Disaster management has a comprehensive network that incorporates a regional administrative system. However there is a significant coordination and communication gap between these three services.

\section{CSSL endeavours to fill the gaps}

In 2021 under the leadership of Prof Srinath Chandrasekera, CSSL established a trauma committee with 6 pillars [policy and governance, prevention, pre-hospital care, in hospital care, rehabilitation and training] to facilitate $\mathrm{MoH}$, in congregating all stakeholders together with a shared vision of trauma system development. Trauma committee leaders met monthly at CSSL headquarter to develop, implement, and assess the progress in developing nationwide integrated, comprehensive trauma systems. This encompasses prehospital, hospital and rehabilitation care with the goal of minimizing the short- and long-term health impacts on trauma victims. Trauma committee of CSSL had multiple round table meetings with WHO Sri Lanka office, MoH, Sri Lanka Medical Association [SLMA], Sri Lanka College of Military Medicine [SLCOMM] and disaster management council to develop a policy plan for next 10 years which is summarized in Table 1. The Committee of Trauma CSSL worked on negotiations, collaborations, and if needed providing resources to address existing communication and administrative gaps. The aim was to develop an excellent trauma care system, which few countries with comparable economic status can claim. As the main workforce, which provides essential trauma care services, membership of the college of surgeons could be an invaluable asset to the $\mathrm{MoH}$ in particular and to the public of Sri Lanka in general in these endeavours. Traditionally, College of surgeons have been playing a pivotal role in training doctors and nurses through a well-established array of trauma courses and it is the strength and backbone of this endeavour. While PTC, NTMC, ATLS are intended for training necessary skills within the golden hour of trauma as a baseline, decision Making in 
Major Trauma [DMMT] course focuses on developing skills for advanced surgical management options for definitive trauma care. Initial trauma care for nurses [ICTN] course is intended to give basic skills in managing initial trauma care for nurses. Further Emergency Sonography for Trauma Care [ESTC] course impart knowledge on ultrasound principles and hands-on experience of performing eFAST. Additionally, CSSL conducts an annual Severe Burns Emergency Management Course [SBEMC] and a Hand surgery workshop.

Above mentioned committees are connected together through the policy and governance committee to spearhead the movement by partnering with $\mathrm{MoH}, \mathrm{WHO}$, other colleges, academia and the public. Further, policy and governance committee is entrusted with development of trauma registry and research. Authors are confident that with the dedicated effort of committee members, CSSL will achieve its objectives within a decade by well-structured short and longterm plans.

Table 1. Trauma sub-committees and their objectives

\begin{tabular}{|c|c|}
\hline Sub committee & Actions planned \\
\hline Policy and governance & $\begin{array}{l}\text { Spearhead the effort with connecting other partners in trauma care delivery and } \\
\text { development. } \\
\text { Additionally, this committee will support the MoH effort in digitizing health records by } \\
\text { providing subject matter expertise to identify minimum data sets, data sources and data } \\
\text { collection techniques related to trauma care. }\end{array}$ \\
\hline Preventive and public health & $\begin{array}{l}\text { To create a greater level of awareness \& commitment among public and decision-making } \\
\text { bodies on injury prevention in automobile, occupational, domestic, and other trauma. } \\
\text { To integrate stakeholders of the prevention of trauma network which include the Ministry } \\
\text { of Health, World Health Organization, Sri Lanka Medical Association, Police department, } \\
\text { Judiciary and other interested parties to develop and implement strategies. }\end{array}$ \\
\hline Prehospital care & $\begin{array}{l}\text { CSSL has already signed an MOU with SUWASERIYA foundation to get involved in training } \\
\text { of ambulance crew, integration of prehospital care system with hospital care system, } \\
\text { providing subject matter expertise required for developing protocols for patient care and } \\
\text { improving efficiency of patient handing over process and research work. }\end{array}$ \\
\hline In hospital care & $\begin{array}{l}\text { To improve in hospital treatment by suggesting necessary resource allocations and } \\
\text { adjusting hospital protocols and designs. Development of trauma manuals for doctors } \\
\text { working in emergency units has already been undertaken. } \\
\text { Introducing a cluster system among regional hospitals for trauma care will be considered } \\
\text { together with a policy and governance subcommittee. The college believes the quality of } \\
\text { trauma care can be improved by such a cluster system. }\end{array}$ \\
\hline Rehabilitation & $\begin{array}{l}\text { The college envisages to establish a full -fledged rehabilitation unit per each province. } \\
\text { Since it is a major financial and logistic undertaking, it needs government blessings and } \\
\text { support from well-wishers. The rehabilitation subcommittee will be working along with } \\
\text { the } \mathrm{MOH} \text { to reach this goal. }\end{array}$ \\
\hline Training & $\begin{array}{l}\text { The college will be expanding its training activities with an aim of providing mandatory } \\
\text { training to all doctors involved in trauma care, especially those in primary care units, } \\
\text { emergency treatment units, accident, and emergency units, surgical SHOs. Further } \\
\text { expansion of training nurses, training of SUWASERIYA paramedical staff, training of three } \\
\text { wheel and taxi drivers and bystander training for "stop the bleed" and team training in } \\
\text { trauma care would be undertaken by college of surgeon in near future }\end{array}$ \\
\hline
\end{tabular}

The Sri Lanka Journal of Surgery 2021; 39(3): 83-93

Acknowledgement

We would like to thank the dedicated effort of all the committee chairs and members in this historical endeavour.

Mihira Banadara, Amila Ratnayake, Bingumal Jayasundara, Mahanama Gunasekera, Nissanka Jayawardane, Hasantha Thambavita.

\section{References}

1. A60_R22-en.pdf [Internet]. [cited 2021 Oct 5]. Available from: https://apps.who.int/iris/bitstream/handle/10665/22596/A60_R 22-en.pdf? sequence $=1 \&$ is Allowed $=y$

2. A H S 2019.pdf [Internet]. [cited 2021 Oct 5]. Available from: http://www.health.gov.lk/moh_final/english/public/elfinder/file s/publications/AHB/AHS\%202019.pdf

3. Vos T, Lim SS, Abbafati C, Abbas KM, Abbasi M, Abbasifard M, et al. Global burden of 369 diseases and injuries in 204 countries and territories, 1990-2019: a systematic analysis for the Global Burden of Disease Study 2019. The Lancet. 2020 Oct 17;396[10258]:1204-22.

4. Mock C, Joshipura M, Arreola-Risa C, Quansah R. An Estimate 
of the Number of Lives that Could be Saved through Improvements in Trauma Care Globally. World J Surg. 2012 May 1;36[5]:959-63.

5. World Bank. Delivering Road Safety in Sri Lanka: Leadership Priorities and Initiatives to 2030 [Internet]. Washington, DC: World Bank; 2020 Feb [cited 2021 Oct 5]. Available from: https://openknowledge.worldbank.org/handle/10986/33341

6. 15_Accident n Emergency.pdf [Internet]. [cited 2021 Oct 5]. Available from:

http://www.health.gov.lk/moh_final/english/public/elfinder/file /publications/publishpolicy/15_Accident $\% 20$ n\%20Emergency.pdf

7. National Council for Road Safety [Internet]. [cited 2021 Oct 5]. Available from:

https://www.transport.gov.lk/web/index.php?option=com content\&view $=$ article\&id $=90 \&$ Itemid $=191 \&$ lang $=e n$

8. PGIM [Internet]. [cited 2021 Oct 5]. Available from: https://pgim.cmb.ac.lk/index.php/md-emergency-medicine/

9. Disaster Management Act [Internet]. [cited 2021 Oct 5]. Available from:

http://www.dmc.gov.lk/index.php?option=com_content\&view= article\&id $=28 \&$ Itemid $=188$ \&lang $=$ en

10.18-2018_E.pdf [Internet]. [cited 2021 Oct 5]. Available from: https://www.srilankalaw.lk/gazette/2018_pdf/18-2018_E.pdf

11.The College of Surgeons of Sri Lanka [Internet]. [cited 2021 Oct 5]. Available from: https://surgeons.lk/

The future of Urological surgery in Sri Lanka The specialty of urological surgery in Sri Lanka commenced as a single unit at the then Colombo General Hospital in 1954. Now it has made vast strides serving needs of the population and currently is in a state of progressive flux with an evolving repertoire of endoscopic, laparoscopic, and open surgical techniques.

The change of demographics across the world and in Sri Lanka, and changing socio-economic trends have caused a rising demand for urological services for illnesses such as malignancies and urinary stone diseases and changes in health-seeking behaviour.

\section{Towards further expansion of expertise}

By the year 2025, Sri Lanka is likely to have 1 urologist per 500,000 population. However, there are restrictions to expansion in the current specialist placement system of the state health sector. Innovative approaches are needed to surmount these limitations and challenges. The concept of sub-specialization according to patient cohorts [e.g. paediatric urology, onco-urology] or types of surgical expertise [e.g. reconstructive urology, robotic/laparoscopic urology], is one of them.

\section{Towards expansion of structure}

The traditional approach of stand-alone urology departments needs to change to cater to the national needs. There should change and evolve towards the next level of service expansion with well-equipped centres of excellence. TAll established key university teaching hospitals need to develop as centres of excellence. Each centre needs to be staffed by $5-10$ urological surgeons with focused sub-specializations and they will be fed by clustered general urology units in the region. The centres of excellence need to be equipped with adequate and excellent infrastructure facilities. General urology cases should shared by consultants in the centre or referred to feeding general urology units in a given cluster. Feeder units would refer the complicated patients to the centre and also carry out basic urology care including the common urological procedures.

The College of Surgeons of Sri Lanka [CSSL] and the Sri Lanka Association of Urological Surgeons [SLAUS] are currently working on a programme where urological surgeons in the state sector who lack facilities for specialized stone surgery can bring in patients for such surgery to a dedicated centre.

Going parallel with the described centres in the state sector, the development of private sector urological services too will be encouraged.

\section{Taking training in urology to the next level}

An overhaul of the current post-MD sub-specialization to urological surgery is long overdue. While this debate is ongoing in the postgraduate programme, the CSSL and the SLAUS have initiated an internationally acceptable exit certification of specialist training in urology. This is bound to elevate the international standing of Sri Lankan urology. Reaching out to international urology associations both regionally and internationally will help to make Sri Lanka an important player in global urology fraternity.

Home grown scientific research, publications and presentations will be facilitated. As a surgical field which is advancing rapidly a reliable centrally held data set by regular national audit has come to the fore. SLAUS has taken the initiative to collect the national urological cancer audit at and plans to roll it out to other urological conditions. Research across all levels of urological practice is encouraged with subsequent presentation and publication.

\section{Dr Suren De Zylva [President] and Dr Kalana Parana Palliya Guruge [Secretary] of Sri Lanka Association of Urological Surgeons}

\section{Progress and Future of Vascular Surgery in Sri Lanka}

Vascular surgery as a standalone specialty has developed in Sri Lanka since the beginning of this millennium. The epidemic of diabetes mellitus and increasing life expectancy in Sri Lanka has resulted in a significant increase in vascular workload in general, and extremity occlusive arterial disease in particular.

Interestingly the bulk of vascular disease presents as lower extremity ulceration in patients with diabetes mellitus and varicose veins. Traditionally, the bulk of this work has been 
dealt with by the general surgeons, but a lack of appreciation of the contribution of ischaemia in the fight against infection in the diabetic foot and the transition to endovenous ablation for varicose veins has resulted in the need for vascular specialists to take over this workload as far as possible. Revascularization of the diabetic foot has radically improved limb salvage and healing and provision of bypass surgery 1 and balloon angioplasty 2 on a regular basis is our goal. The paucity of catheter laboratory facilities in operating theatres is a major hinderance to the provision of endovascular care in Sri Lanka. We propose to transform vascular theatres into hybrid [open-endo] theatres in the near future. Nevertheless, the role of endovascular aneurysm repair [EVAR], balloons, atherectomy devices and stents are costly and less durable alternatives to open surgery that need careful evaluation with clear guidelines for use in Sri Lanka.

We plan to introduce Resuscitative Endovascular Balloon Occlusion of the Aorta [REBOA] 3 in the case of major trauma which is expected to reduce mortality from massive haemorrhage.

There is also a need to develop at least one centre of excellence in each province to deal with difficult, complex, and recurrent vascular surgical problems to offer the best care to patients. Further, setting up of multidisciplinary teams that include podiatrists, orthotists and medical specialists in tertiary centres will be pursued to optimize and sustain best outcomes.

With the objective of improving the quality of surgery for vascular disease, Sri Lanka Society for Vascular Surgery [SLSVS] was established in 2017. By providing a platform for sharing latest developments in vascular disease and surgery, the SLSVS hopes to provide its members with the opportunities to learn from experts in the field as well as sharing knowledge and learning from each other's experiences. SLSVS would ensure the provision of new knowledge and coordination of care which ultimately would benefit all those with vascular disease in Sri Lanka. There is paucity in data on the practices, safety, and efficacy of vascular interventions in Sri Lanka at a national level. The need to collect our own data and make the practice of vascular surgery evidence guided cannot be overemphasized. Our current experience with single centre registries will be used to cover the rest of the island in the coming decade. Similarly the SLSVS propose to setup vascular registries and research collaborations in South Asia.

There is much work to be done in terms of policy making, training, service provision and research in vascular surgery in Sri Lanka. The process has been started and the need is to sustain the effort and move the specialty forward so that vascular surgery in Sri Lanka will be able to match the best practices in the world and provide quality care to all.

Prof S.M. Wijeyaratne SM [President] and Dr M.R.N Cassim [Secretary], Sri Lanka Society for Vascular Surgery

\section{References}

1. Wijeyaratne M, Cassim R, Bradbury A, Hyrin A, Jayawickrema B, Weerasekera A, Hettiarachchi M, Sirimanna C, Galapaththy C. Clinical Outcomes Following Lower Extremity Vein Bypass for Chronic Limb Threatening Ischaemia [CLTI] at the University of Colombo, Sri Lanka. Eur J Vasc Endovasc Surg. 2020 Oct;60[4]:560-566. doi: 10.1016/j.ejvs.2020.06.039. Epub 2020 Aug 7. PMID: 32778492.

2. Cassim MRN, Godahewa S, Paviththiran S, Wijeyaratne SM. Percutaneous transluminal lower limb angioplasty [PTA] for chronic limb threatening ischaemia [CLTI] in a low resource setting - 4 year experience. Sri Lanka Journal of Surgery. 2020;38[3]:13-20. DOI: http://doi.org/10.4038/sljs.v38i3.8789

3. Cassim MRN, Ratnayake AS, Malalasekera A, McGreevy DT, Wijeyaratne M, Hörer TM. Resuscitative endovascular balloon occlusion of aorta [REBOA]: expanding the window of survival in massive bleeding. Sri Lanka Journal of Surgery. 2021;39[2]:1-4. 